\title{
Análise, em dados em painel, de efeitos de despesas sobre a taxa de homicídio juvenil no Brasil
}

Analysis, in panel data, of expenditure effects on the juvenile homicide rate in Brazil

Análisis, en datos de panel, de los efectos del gasto en la tasa de homicidios juveniles en Brasil

Recebido: 28/09/2021 | Revisado: 01/10/2021 | Aceito: 01/10/2021 | Publicado: 03/10/2021

Tito Belchior Silva Moreira

ORCID: https://orcid.org/0000-0002-2382-1480

Universidade Católica de Brasília, Brazil

E-mail: titoeco@yahoo.com.br

Lacerda Sipriano Elias

ORCID: https://orcid.org/0000-0002-4484-2950

Universidade Católica de Brasília, Brazil

E-mail: lacerdastones@gmail.com

\begin{abstract}
Resumo
Este artigo avalia, empiricamente, os efeitos das despesas públicas sobre as taxas de homicídios da população jovem brasileira. O estudo realiza uma abordagem com dados em painel em três modelos, pooled, efeito fixo e efeito aleatório, por unidades da federação brasileira no período 2002-2014. Discute-se, utilizando outras variáveis explicativas, o impacto das despesas em assistência e previdência sobre a taxa de homicídio juvenil na faixa etária dos 15 aos 29 anos de idade. Com base nos três diferentes modelos em painel, os resultados atestam a hipótese de que aumentos nessas despesas produzem reduções nas taxas de homicídio dessa população. As variáveis que representam a pobreza, a escolaridade, o desemprego, a despesa com justiça e cidadania, o consumo de energia elétrica e a renda média, também, são estatisticamente significantes no estudo e, no geral, confirmam os sinais esperados.
\end{abstract}

Palavras-chave: Homicídio; Despesa pública; Dados em painel.

\begin{abstract}
This article empirically assesses the effects of public spending on homicide rates in the Brazilian youth population. The study performs an approach with panel data in three models, pooled, fixed effect and random effect, by Brazilian federation units in the period 2002-2014. Using other explanatory variables, the impact of expenditure on assistance and social security on the juvenile homicide rate in the 15 to 29 age group is discussed. Based on the three different panel models, the results support the hypothesis that increases in these expenses produce reductions in the homicide rates of this population. The variables that represent poverty, education, unemployment, expenditure on justice and citizenship, electricity consumption and average income are also statistically significant in the study and, in general, confirm the expected signs.
\end{abstract}

Keywords: Homicide; Public expense; Panel data.

\section{Resumen}

Este artículo evalúa empíricamente los efectos del gasto público en las tasas de homicidio en la población joven brasileña. El estudio realiza un abordaje con datos de panel en tres modelos, agrupado, efecto fijo y efecto aleatorio, por unidades de la federación brasileña en el período 2002-2014. Utilizando otras variables explicativas, se discute el impacto del gasto en asistencia y seguridad social en la tasa de homicidios juveniles en el grupo de edad de 15 a 29 años. Con base en los tres modelos de panel diferentes, los resultados apoyan la hipótesis de que los aumentos en estos gastos producen reducciones en las tasas de homicidio de esta población. Las variables que representan pobreza, educación, desempleo, gasto en justicia y ciudadanía, consumo eléctrico e ingreso promedio también son estadísticamente significativas en el estudio y, en general, confirman los signos esperados.

Palabras clave: Homicidio; Gasto público; Panel de datos.

\section{Introdução}

A população brasileira presencia, diariamente, o surgimento das inovações tecnológicas e, de fato, é uma realidade mundial desse século. Contudo, alguns fenômenos dificultam o desenvolvimento e geram entraves para o êxito e, dois desses obstáculos são a insegurança e as elevadas taxas de homicídio. 
Homicídios produzem angústias e as famílias vitimadas sofrem eternamente com esse mal, pois perdem seus entes queridos e esses deixam de contribuir para o crescimento do país e para a alegria familiar.

Viano (2007) comenta que o homicídio é um fenômeno que apresenta complexidade e representa o crime de maior gravidade, cuja solução tem dentro das alternativas possíveis, uma abordagem pela perspectiva da vítima.

Segundo Atlas da violência (2021), no ano de 2019 ocorreu o registro de 45.503 homicídios e desses, 23.327 foram de jovens com idades distribuídas na faixa etária dos 15 aos 29 anos de idade, ou seja, aproximadamente, 51,26\% do total de vítimas foram jovens. Uma estatística alarmante, pois são talentos que não vão contribuir para o sucesso familiar e para o desenvolvimento da nação.

Esse cenário é assustador e precisa de soluções urgentes. Famílias e sociedade precisam de políticas públicas que garantam a atuação do papel social de forma harmônica e isenta de violência, pois o bem estar gera tranquilidade e desenvolvimento para todos os agentes.

Segundo Alves, Oliveira e da Silva (2017), um dos objetivos dos governos é garantir a melhoria da qualidade de vida da população, cuja atuação é fato que tem relação direta com o desenvolvimento econômico e, concretamente, observado em vários países desenvolvidos.

Moraes e Chaves (2020) sugerem que políticas públicas eficazes e eficientes para eliminação, ou ainda, a redução da violência precisam focar na diminuição das vulnerabilidades das famílias e da sociedade, além de investimentos significativos em educação com qualidade.

Colombaroli e Agapito (2016) sugerem que ações fundamentadas em prevenções de delito e planejamento integrado, desenvolvido pelos componentes da segurança pública, são aspectos relevantes para alcançar o êxito no combate à criminalidade.

Loureiro, Mendonça e Sachsida (2003) sugerem que estratégias diferenciadas de prevenção à criminalidade podem ser elaboradas para cada modalidade de crime e no caso dos violentos, os autores indicam que a aproximação do indivíduo com a família, do ambiente comunitário onde fixou residência e de Deus parecem ser ações adequadas para promover a redução desse tipo de crime.

O contexto sugere a implementação de políticas públicas inovadoras e assim, são necessários estudos e o enriquecimento da literatura, sobretudo a partir das reflexões dos acontecimentos diários e da interpretação dos indicadores registrados.

Essa pesquisa discute os impactos das despesas em assistência e previdência sobre a taxa de homicídios da população jovem brasileira, pertencente ao grupo na faixa etária de 15 a 29 anos de idade no período 2002-2014, utilizando dados em painel com efeito fixo, efeito aleatório e pooled, por unidades da federação. As variáveis explicativas utilizadas no estudo são o coeficiente de Gini, a escolaridade, a pobreza, a taxa de desemprego, o consumo de energia elétrica residencial, a renda média de todos os trabalhos, as despesas em ciência e tecnologia, educação e cultura, saúde e saneamento, essenciais à Justiça e o direito à cidadania e, assistência e previdência. A despesa em assistência e previdência, como fato gerador de renda e aspectos sociais familiares e coletivos é a nossa variável explicativa de interesse e fundamenta nossa hipótese, pois acreditamos evidenciar uma relação indireta com a taxa de homicídios da população estudada.

Esse trabalho está distribuído em cinco seções. Além dessa introdução, a revisão da literatura é apresentada na seção 2, a metodologia, que inclui base de dados e modelos econométricos, está na seção 3, resultados e discussão na seção 4 e, na seção 5 são apresentadas as considerações finais. 


\section{Revisão da Literatura}

Melhorar os indicadores educacionais requer coleta e análise de dados de diversos aspectos socioeconômicos, a observação de pesquisas de sucessos evidenciadas na literatura e nas experiências construídas, além de inúmeros debates coletivos, com participação a da sociedade. Dessa forma, é possível desenhar e implementar políticas públicas integradas de planejamento, ações e investimentos que promovam o êxito nas propostas e oferta de serviços públicos eficazes, eficientes e efetivos.

Conforme dados do Atlas da Violência (2021), no Brasil foram registrados em 2017, 2018 e 2019, respectivamente $35.783,30.873$ e 23.327 homicídios sofridos por jovens na faixa etária de 15 a 29 anos de idade e, embora uma redução seja evidenciada, os números ainda retratam uma imensa realidade de insegurança.

A violência gera impactos em diversos setores da sociedade. Para Paula (2010) é um fenômeno gerador de debates em diversificados espaços sociais, temporais e situacionais. Ademais, segundo enuncia Fortunato (2009) é um problema de saúde pública das mais altas proporções, que produz efeitos significativos na mortalidade e morbidade que são sentidos pela população.

Wailselfisz (2016), considerando os anos de 1980 e 2014, constatou um aumento de 415,1\% no número de vítimas de homicídio e de $592,8 \%$ por algum tipo de arma de fogo. Analisando a soma dos valores absolutos do período 2010-2014, constatou que o número total de homicídios representou 85,8\% do total de vítimas por algum tipo de arma de fogo, mas incorporando as causas indeterminadas aos homicídios esse percentual fica próximo de 95\%, um aumento superior ao crescimento populacional no período.

Nogueira, Gomes e Barbosa (2018) constataram uma redução nas taxas de homicídio no Estado do Paraná, no período 2010-2015, no entanto ficaram evidenciados que os óbitos de adultos e o uso de arma de fogo se mostraram predominantes.

Spaniol, Júnior e Rodrigues (2020) analisaram de forma bibliográfica e documental, as Políticas Públicas de Segurança já adotadas e concluíram que há necessidade de uma continuidade e maior participação social em suas construções para que ocorram reduções e maior eficácia na prevenção da criminalidade.

Políticas de segurança públicas orientadas por TICs inovadoras, experiências de sucesso observadas e participação social podem contribuir para um avanço na redução dos índices de homicídio.

Cerqueira e Lobão (2004), analisando os determinantes da criminalidade, evidenciaram uma complexidade desse fenômeno o que dificulta e reduz a escolha de variáveis explicativas. No entanto, aspectos culturais, regionais e, dependendo, do momento histórico vivenciado, algumas variáveis podem ser decisivas para a explicação da dinâmica criminal.

Cano e Ribeiro (2007) argumentam que a tipificação do homicídio, o perfil das vítimas e o diagnóstico da localidade do crime são aspectos importantes para a elaboração de uma política pública de prevenção de homicídios.

Sachsida e Mendonça (2013) ressaltam, ainda, que o êxito no combate à criminalidade pode ser obtido sem mudanças substanciais na estrutura socioeconômica e, nesse sentido, elevar a taxa do efetivo policial funciona e é capaz de diminuir as taxas de homicídios.

Carvalho e Taques (2014,) pesquisando explicações para a criminalidade no Brasil no período 2001-2009 e utilizando painel estático com efeitos fixos e aleatórios, encontraram resultados que sugerem a ocorrência de menores taxas de homicídio, variável dependente, quando são realizados maiores gastos em segurança, uma das variáveis explicativas.

Nesse sentido, investigar a motivação e a dinâmica dos crimes é fator importante para esclarecimentos e prisões. A racionalidade na execução do crime é outro fator importante, pois segundo Becker (1968), o autor do crime realiza uma análise de custo benefício para a decisão de cometimento da ação criminosa. O modelo proposto pelo autor considera as expressões: 
Em Becker (1968), $H_{\mathrm{i}}=H_{\mathrm{i}}\left(O_{\mathrm{i}}\right)$,

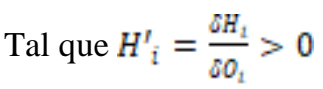

Onde $H_{\mathfrak{i}}$ representa o prejuízo para a i-ésima atividade infratora e $O_{\hat{i}}$, o nível dessa atividade.

Na construção do modelo é adotada a crença de que diversos membros da sociedade sofrem os prejuízos, o que conduz à motivação para restringir a atividade delituosa.

Conforme Becker (1968), o nível da atividade delituosa tende a elevar o montante do prejuízo e o valor social do ganho do infrator. Ou seja:

$$
G=G(0)
$$

e,

$$
G^{\prime}=\frac{\delta G}{\delta 0}>0
$$

Ademais, $D(0)=H(0)-G(0)$, representa o prejuízo para a sociedade. Ademais, o ganho marginal do infrator é decrescente, enquanto o prejuízo social marginal é crescente, com a prática de um delito adicional. Dessa forma,

$D^{\mathrm{m}}=\mathrm{H}^{\mathrm{m}}-G^{\mathrm{m}}>0$, onde $G$ representa o ganho do infrator e $D$, o dano social. Quanto mais alta a especialização dos serviços e equipamentos destinados ao combate dos delitos, mais elevada será a eficácia e eficiência para solucionar e prender os infratores. Dessa forma, as funções são enunciadas:

$$
C=C(A)
$$

e,

$$
C^{\prime}=\frac{B C}{B A}>0
$$

Onde, $C$ representa os Custos do Estado e,

$$
A=f(m, r, c),
$$

Onde, $m$ representa trabalho, $r$ representa materiais e $c$, capital.

Hamberger, Araujo e Valle (2019), a partir de uma análise de dados em painel (pooled, efeito fixo e efeito aleatório), no período 2005-2007, encontram resultados que mostram que gastos com esportes impactam negativamente a criminalidade nos municípios da Região do Triângulo Mineiro e Alto Paranaíba.

A pesquisa de Seillier (2012), com dados em painel no período 2001-2005 para estudar a criminalidade nas Unidades da Federação no Brasil, em um modelo de regressões aparentemente não relacionadas, observam resultados que sugerem que ao reduzir taxas de escolaridade, são gerados aumentos nas taxas de homicídio. 
Em modelos estudados por Loureiro, Moreira e Ellery (2017), o coeficiente de Gini e a taxa de pobreza são significativos para explicar a taxa de homicídio. Assim, na pesquisa, aumentos no coeficiente de Gini produzem aumentos na taxa de homicídios, enquanto aumentos na taxa de pobreza produzem uma redução. Goha, Kaliappan e Ishak, (2018), em GMM com painel dinâmico, apresentam uma relação positiva entre as variáveis, crime e desigualdade de renda.

Oliveira (2016) utilizando dados em painel (PVAR) ao estudar relações entre economia e criminalidade no período 1990-2010 nas 27 Unidades da Federação, observou que aumentos na renda per capita produzem impactos negativos na variável dependente taxa de homicídios.

Pinto, Farias, Costa e Lima (2018), em modelo de dados em painel e Métodos dos Momentos Generalizados (GMM) nas 27 UFs, período 2001-2014, analisa a variável dependente taxa de homicídio e os resultados mostram significância nas variáveis explicativas escolaridade e renda média, no entanto, a primeira apresenta sinal negativo e a segunda, positivo. Nesse estudo, o grau de informalidade apresenta coeficiente positivo, contudo ao nível de 10\%, podendo não explicar a criminalidade.

Furqan e Mahmood (2020), em dados em painel com efeito fixo, mostram uma relação inversa entre educação e taxa de homicídio e argumentam que a educação contribui para a formação de um ser mais ético, que evita atividades ilegais. Os autores adicionam que PIB per capita e taxas de homicídios apresentam relação inversa, enquanto aumentos no desemprego produzem aumentos nessa modalidade de crime.

Souza Lucas, Cunha e Bondezan (2020), ao analisar aspectos socioeconômicos que determinam impactos na criminalidade no Estado do Paraná, mostram que o alto grau de desigualdade econômica e altas taxas de desemprego tendem para taxas de homicídios mais altas.

Olini, Daniel, Dalfovo, Orlandi e Shikida (2018), em estudo com análise espacial para o Estado do Mato Grosso no período 2000-2010, mostram uma relação direta entre desigualdade de renda e taxa de homicídios nas localidades estudadas.

Ervilha e Lima (2019), em dados em painel com efeito fixo para estudar os fatores que determinam a criminalidade em municípios de Minas Gerais no Brasil, comentam que as lacunas observadas no mercado de trabalho podem estar agravando a criminalidade no Estado mineiro.

Regateiro, Ramos, Souza e Mello (2021), avaliando criminalidade no Estado do Pará no período 2017-2019, constatam que grande parte dos municípios paraenses apresentou redução nos índices de criminalidade, contudo aqueles que se encontram destacados no ranking com os índices mais altos, apresentam reduzidas taxas de ocupação para o trabalho.

Máquina, Maria, Nhogo e Come (2021), analisam criminalidade nos municípios paulistas no Brasil e constatam que a combinação de extrema pobreza e inacessibilidade à educação, contribuiu para elevar as taxas de analfabetismo nas localidades em estudo, por conseguinte têm sido fatores importantes e determinantes para aumentos da violência urbana e, assim, do número de homicídio.

Oliveira (2019) pesquisa os impactos da criminalidade em Fortaleza - Ceará e observa uma relação inversa entre renda média e taxas de homicídio nos bairros estudados.

\section{Metodologia}

Kauark, Manhães e Medeiros (2010) destacam que a análise quantificável faz utilização de recursos e técnicas estatísticas, das quais a análise de regressão é um processo caracterizador da pesquisa quantitativa. Nessa pesquisa quantitativa é utilizado o método indutivo para a abordagem do assunto. Segundo Marconi e Lakatos (2017), esse método tem maior abrangência ao abordar fatos e fenômenos, pois busca alcançar as leis e teorias gerais partindo de constatações particulares.

O objetivo dessa pesquisa é descritivo e de acordo com Gil (2008), a descrição dos aspectos característicos de um 
fenômeno ou a determinação das relações entre as variáveis abordadas representa o objetivo principal desse tipo de pesquisa.

Essa seção está dividida em duas subseções. A subseção 3.1 apresenta as fontes e as definições dos dados utilizados no trabalho e a seção 3.2 apresenta o modelo econométrico adotado.

\subsection{Base de dados}

Nessa pesquisa, estamos interessados em observar e analisar os fatores que produzem efeitos na taxa de homicídio juvenil, isto é, das pessoas pertencentes ao grupo da faixa etária dos 15 aos 29 anos de idade no período 2002-2014 para todas as unidades federativas do Brasil, utilizando dados em painel em pooled, efeito fixo e efeito aleatório. O quadro 1, destacado a seguir, descreve as variáveis utilizadas, as fontes de coleta dos dados oficiais, o período e o sinal esperado nos resultados. O modelo econométrico adotado é apresentado na subseção 3.2.

Quadro 1 - Fontes e definições dos dados adotados.

\begin{tabular}{|c|c|c|c|c|}
\hline Variável & Período & Fonte & & $\begin{array}{l}\text { Sinal } \\
\text { esperado }\end{array}$ \\
\hline $\begin{array}{l}\text { Taxa de homicídios } \\
\text { de jovens de } 15 \text { a } \\
29 \text { anos do sexo } \\
\text { masculino } \\
\text { (homicjov) }\end{array}$ & $2002-2014$ & $\begin{array}{l}\text { IPEA } \\
\text { Dados originais } \\
\text { (SIM- } \\
\text { DATASUS })\end{array}$ & $\begin{array}{l}\text { "Óbito por causa externa ou não natural, indiferente } \\
\text { do tempo entre o evento lesivo e a morte } \\
\text { propriamente, é categorizado como consequente de } \\
\text { lesão provocada por violência (acidentes, } \\
\text { homicídios, suicídios ou morte suspeita). Neste } \\
\text { caso, a taxa por } 100.000 \text { habitantes é calculada } \\
\text { através da divisão do indicador principal (número } \\
\text { de homicídios de jovens de } 15 \text { a } 29 \text { anos do sexo } \\
\text { masculino) pelo total da população em questão, } \\
\text { sendo este resultado multiplicado por 100.000. } \\
\text { Fonte: Os dados originais são provenientes do SIM- } \\
\text { DATASUS. Até } 1995 \text { as informações são do CID9. } \\
\text { A partir de } 1996 \text { são do CID10. Elaboração } \\
\text { Ipeadata: Cálculo da Taxa, divisão do grupo } \\
\text { populacional multiplicado por } 100.000 \text { pela } \\
\text { população de referência". }\end{array}$ & \\
\hline $\begin{array}{l}\text { Anos de estudo - } \\
\text { média - pessoas } 25 \\
\text { anos e mais. } \\
\text { (escol) }\end{array}$ & $2002-2014$ & IPEADATA & $\begin{array}{l}\text { "Razão entre o somatório do número de anos de } \\
\text { estudo completados pelas pessoas que tem } 25 \text { ou } \\
\text { mais anos de idade e o numero de pessoas nessa } \\
\text { faixa } \\
\text { Unidade: Ano. }\end{array}$ & Negativo \\
\hline $\begin{array}{c}\text { Despesas por } \\
\text { função - } \\
\text { Assistência e } \\
\text { Previdência - } \\
\text { Estadual. } \\
\text { (assprev). }\end{array}$ & $2002-2014$ & $\begin{array}{l}\text { IPEADATA/Mi } \\
\text { nistério da } \\
\text { Fazenda/ } \\
\text { Secretaria do } \\
\text { Tesouro } \\
\text { Nacional. }\end{array}$ & $\begin{array}{l}\text { "Estão discriminadas as despesas segundo rubrica: } \\
\text { Assistência e Previdência". Unidade: R \$ (por } \\
\text { bilhão) }\end{array}$ & Negativo \\
\hline $\begin{array}{l}\text { Despesas por } \\
\text { função - ciência e } \\
\text { tecnologia - } \\
\text { Estadual. } \\
\text { (cietec). }\end{array}$ & $2002-2014$ & $\begin{array}{l}\text { IPEADATA/Mi } \\
\text { nistério da } \\
\text { Fazenda/ } \\
\text { Secretaria do } \\
\text { Tesouro } \\
\text { Nacional. }\end{array}$ & $\begin{array}{l}\text { "Estão discriminadas as despesas segundo rubrica: } \\
\text { Ciência e Tecnologia". Unidade: R\$ (por bilhão). }\end{array}$ & Negativo \\
\hline $\begin{array}{l}\text { Despesas } \quad \text { por } \\
\text { função - saúde } \mathrm{e} \\
\text { saneamento } \\
\text { Estadual. } \\
\text { (sausan). }\end{array}$ & $2002-2014$ & $\begin{array}{c}\text { IPEADATA/Mi } \\
\text { nistério da } \\
\text { Fazenda/ } \\
\text { Secretaria do } \\
\text { Tesouro } \\
\text { Nacional. }\end{array}$ & $\begin{array}{l}\text { "Estão discriminadas as despesas segundo rubrica: } \\
\text { Saúde e Saneamento". Unidade: R \$ (por bilhão). }\end{array}$ & Negativo \\
\hline
\end{tabular}




\begin{tabular}{|c|c|c|c|c|}
\hline $\begin{array}{l}\text { Taxa } \quad \text { de } \\
\text { desemprego } \\
(\text { desemp) }\end{array}$ & $2002-2014$ & IBGE & $\begin{array}{l}\text { "Percentual das pessoas que procuraram, mas não } \\
\text { encontraram ocupação profissional remunerada } \\
\text { entre todas aquelas consideradas "ativas" no } \\
\text { mercado de trabalho, grupo que inclui todas as } \\
\text { pessoas com } 10 \text { anos ou mais de idade que estavam } \\
\text { procurando ocupação ou trabalhando na semana de } \\
\text { referência da Pesquisa Nacional por Amostra de } \\
\text { Domicílios (Pnad)". }\end{array}$ & Positivo \\
\hline $\begin{array}{l}\text { Coeficiente de } \\
\text { Gini. } \\
\text { (gini) }\end{array}$ & $2002-2014$ & IPEADATA & $\begin{array}{l}\text { Desigualdade de renda - Coeficiente de Gini. } \\
\text { "Mede o grau de desigualdade na distribuição da } \\
\text { renda domiciliar per capita entre os indivíduos. Seu } \\
\text { valor pode variar teoricamente desde } 0 \text {, quando não } \\
\text { há desigualdade (as rendas de todos os indivíduos } \\
\text { têm o mesmo valor), até } 1 \text {, quando a desigualdade é } \\
\text { máxima (apenas um indivíduo detém toda a renda } \\
\text { da sociedade e a renda de todos os outros } \\
\text { indivíduos é nula). Série calculada a partir das } \\
\text { respostas à Pesquisa Nacional por Amostra de } \\
\text { Domicílios(Pnad/IBGE)" }\end{array}$ & Positivo \\
\hline $\begin{array}{c}\text { Pobreza - } \\
\text { proporção de } \\
\text { domicílios pobres } \\
(\text { pob })\end{array}$ & $2002-2014$ & IPEADATA & $\begin{array}{l}\text { "Proporção de domicílios com renda domiciliar per } \\
\text { capita inferior à linha de pobreza. A linha de } \\
\text { pobreza aqui considerada é o dobro da linha de } \\
\text { extrema pobreza, uma estimativa do valor de uma } \\
\text { cesta de alimentos com o mínimo de calorias } \\
\text { necessárias para suprir adequadamente uma pessoa, } \\
\text { com base em recomendações da FAO e da OMS. } \\
\text { São estimados diferentes valores para } 24 \text { regiões do } \\
\text { país. Série calculada a partir das respostas à } \\
\text { Pesquisa Nacional por Amostra de Domicílios } \\
\text { (Pnad/IBGE)" }\end{array}$ & Positivo \\
\hline $\begin{array}{c}\text { Despesas por } \\
\text { função - educação e } \\
\text { cultura - Estadual. } \\
\text { (despec). }\end{array}$ & $2002-2014$ & $\begin{array}{l}\text { IPEADATA/Mi } \\
\text { nistério da } \\
\text { Fazenda/ } \\
\text { Secretaria do } \\
\text { Tesouro } \\
\text { Nacional. } \\
\end{array}$ & $\begin{array}{l}\text { "Estão discriminadas as despesas segundo rubrica: } \\
\text { Educação e Cultura". } \\
\text { Unidade: R\$ (por bilhão). }\end{array}$ & Negativo \\
\hline $\begin{array}{c}\text { Despesas por } \\
\text { função - essencial à } \\
\text { Justiça e Direito da } \\
\text { Cidadania - } \\
\text { Estadual. } \\
\text { (despjuscid). }\end{array}$ & $2002-2014$ & $\begin{array}{l}\text { IPEADATA/Mi } \\
\text { nistério da } \\
\text { Fazenda/ } \\
\text { Secretaria do } \\
\text { Tesouro } \\
\text { Nacional. }\end{array}$ & $\begin{array}{l}\text { "Estão discriminadas as despesas segundo rubrica: } \\
\text { Essencial a Justiça e Direito da Cidadania". } \\
\text { Unidade: R\$ (por bilhão). }\end{array}$ & Negativo \\
\hline $\begin{array}{l}\text { Renda média de } \\
\text { todos os trabalhos } \\
\text { (rendam) }\end{array}$ & $2002-2014$ & $\begin{array}{l}\text { IPEADATA/ } \\
\text { IBGE }\end{array}$ & $\begin{array}{l}\text { "Média, por pessoa ocupada, dos rendimentos } \\
\text { mensais brutos totais em dinheiro recebidos em } \\
\text { todos os trabalhos no mês de referência da Pesquisa } \\
\text { Nacional por Amostra de Domicílios (Pnad/IBGE). } \\
\text { No caso de empregados, considera-se a } \\
\text { remuneração obtida no mês de referência, tendo ou } \\
\text { não trabalhado o mês completo. No caso de } \\
\text { rendimento variável, média da remuneração mensal } \\
\text { recebida. Para empregadores e trabalhadores por } \\
\text { conta própria, retirados no mês de referência, ou } \\
\text { seja, o rendimento bruto menos as despesas } \\
\text { efetuadas com salários de empregados, matéria- } \\
\text { prima, energia elétrica, telefone etc., sendo ainda } \\
\text { considerada, no caso de rendimento variável, a } \\
\text { retirada média mensal. Em nenhum caso é } \\
\text { computadas a parcela referente ao 13o. salário }\end{array}$ & Negativo \\
\hline
\end{tabular}




\begin{tabular}{|c|c|c|c|c|}
\hline & & & $\begin{array}{l}\text { (14o., 15o. etc.), nem a parcela referente à } \\
\text { participação nos lucros paga pelas empresas aos } \\
\text { empregados. Valores reais expressos aos preços } \\
\text { vigentes no mês de referência da última Pnad } \\
\text { disponível, calculados a partir dos microdados da } \\
\text { pesquisa e atualizados conforme o deflator para } \\
\text { rendimentos da Pnad apresentado pelo Ipeadata. } \\
\text { Elaboração: Disoc/IPEA". Unidade: R\$ (por } \\
\text { milhar). }\end{array}$ & \\
\hline $\begin{array}{l}\text { Consumo de } \\
\text { energia elétrica- } \\
\text { residencial. } \\
\text { (consel) }\end{array}$ & $2002-2014$ & $\begin{array}{l}\text { IPEADATA/ } \\
\text { Ministério de } \\
\text { Minas e } \\
\text { Energia, } \\
\text { Balanço } \\
\text { Energético } \\
\text { Nacional } \\
\text { (MME) }\end{array}$ & $\begin{array}{l}\text { "Fonte: Para } 1961 \text { a 1975: Departamento de Águas } \\
\text { e Energia Elétrica. Apud: Anuário Estatístico do } \\
\text { Brasil, diversos anos, IBGE. Obs.: A soma dos } \\
\text { estados não, necessariamente, coincide com o total } \\
\text { Brasil, devido aos dados do Brasil incluir } \\
\text { estimativas de empresas que não tiveram } \\
\text { informações por estados. Em } 1997 \text { não existe dado } \\
\text { por UF" Unidade: MWh }\end{array}$ & Negativo \\
\hline
\end{tabular}

Fonte: Autores.

O método de construção realiza uma abordagem com dados em painel em pooled, efeito aleatório e efeito fixo. Segundo Gujarati (2019), os modelos utilizados para estudar as entidades que pertencem ao mesmo conjunto, ao longo do tempo, são chamados de modelos de regressão de dados em painel. Conforme enuncia o autor, ao assumir que para cada indivíduo, o coeficiente específico individual Bli seja fixo no tempo, tem-se o efeito fixo e, efeito aleatório caso esse coeficiente seja uma variável randomizada com valor médio de B1.

Hausman (1978) descreve a definição do teste para a verificação de qual dos dois modelos, efeito fixo ou efeito aleatório é o mais apropriando e, conforme o autor, ao aceitar a hipótese nula o efeito aleatório é o mais indicado e, em caso de rejeição, o efeito fixo. Fávero e Belfiore (2021) complementam que o modelo pooled é uma estimação mais simplificada de um modelo longitudinal de regressão, que considera a base de dados como uma enorme cross-section na forma mesclada, ou seja, empilhada, fazendo uso dos Mínimos Quadrados Ordinários.

\subsection{Modelo econométrico}

Nessa pesquisa, o modelo econométrico estimado relaciona a variável dependente, ou seja, a taxa de homicídio de jovens pertencentes à população da faixa etária dos 15 aos 29 anos de idade, com as variáveis explicativas, no qual a principal variável de interesse é a despesa com assistência e previdência. A equação dessa despesa do conjunto em estudo está definida a partir de dados em painel conforme enunciado a seguir.

$H j o_{i t}=\beta x_{i t}+\gamma_{t}+v_{i t}$ para $i=1_{s \ldots,} 27 ; t=1, \ldots 13$

em que $H j o_{\text {it }}$ é a taxa de homicídio de indivíduos jovens pertencente à faixa etária dos 15 aos 29 anos de idade, da $i$-ésima Unidade da Federação no período t. A matriz contém intercepto, $x_{i t}$ representa o vetor de variáveis explicativas, $v_{i t}$ é o termo aleatório e $\gamma_{t}$ visa captar efeitos específicos no tempo. Segundo a metodologia para dados em painel, define-se ainda que $v_{i t}=\alpha_{i}+u_{i t}$, no qual $\alpha$ é um termo estocástico próprio das unidades. Generalizando:

$H j o_{i t}=\beta x_{i t}+\gamma_{t}+\alpha_{i}+u_{i t}$ para $i=1, \ldots, 27: t=13$ 
Assim, $\hat{i}$ representa a $\hat{i}$-ésima unidade de corte transversal e $t$ o $t$-ésimo período de tempo. Se cada unidade de corte transversal estiver presente o mesmo número de observações de séries temporais, então esse painel recebe a denominação de painel em equilíbrio.

Segundo Wooldridge (2010), a abordagem clássica de dados em painel busca verificar se o componente individual ( $\propto)$ é correlacionado, ou não, com algum regressor. No primeiro caso, o modelo deve ser estimado por meio da aplicação de um estimador denominado de efeito fixo. No segundo caso, o mais indicado é estimar o modelo por efeito aleatório. Para se verificar qual das duas hipóteses é a que melhor se aplica, emprega-se o teste de Hausman já citado anteriormente.

Segundo Wooldridge (2010) a estimação de $H_{j} o_{\text {it }}$ depende das premissas que são determinadas a respeito do intercepto, dos coeficientes angulares e do termo de erros, $u_{i t}$.

Nesse estudo estamos considerando o modelo:

$H_{j o} o_{i t}=f\left(x_{1,} x_{2}, x_{3}, x_{4}, x_{5}, x_{6}, x_{7,} x_{8}, x_{9}, x_{10}, x_{11},\right)$

Hjo it = taxa de homicídios de jovens pertencentes à população de 15 a 29 anos de idade.

$x_{1}=$ escolaridade, média de anos de estudo para pessoas na faixa etária de 25 anos ou mais.

$x_{2}=$ proporção de domicílios com renda domiciliar per capita inferior à linha de pobreza.

$x_{3}=$ desigualdade de renda, coeficiente de Gini.

$x_{4}=$ taxa de desemprego .

$x_{5}=$ despesas em ciência e tecnologia.

$x_{6}=$ despesas relacionadas à essencialidade à Justiça e direito à cidadania.

$x_{7}=$ despesas em assistência e previdência.

$x_{8}=$ consumo de energia elétrica residencial .

$x_{9}=$ renda média de todos os trabalhos.

$x_{10}=$ despesas em educação e cultura.

$x_{11}=$ despesas em saúde e saneamento.

$H j o_{i t}=C_{i t}+\beta_{1}$ escol $+\beta_{2}$ pob $_{i t}+\beta_{3}$ gini $_{i t}+\beta_{4}$ desemp $_{i t}+\beta_{5}$ cietec $_{i t}+\beta_{6}$ despjuscid $+\beta_{7}$ assprev $+\beta_{8}$ consel + $\beta_{9}$ rendam $+\beta_{10}$ despec $+\beta_{11}$ sausan $+u_{\text {it }}$

, com $i=1,2,3, \ldots, 27$ et $=2002,1994,1995, \ldots, 201$

Os dados coletados são utilizados para a construção do modelo econométrico definido acima. Os três modelos em dados em painel, pooled, efeito fixo e efeito aleatório, consideram a taxa de homicídio juvenil como variável dependente e o restante das variáveis indicados no Quadro 1, são tomadas como variáveis explicativas. O modelo 1 traz uma abordagem em pooled, o modelo 2 em efeito aleatório e o modelo 3, em efeito fixo.

\section{Resultados e Discussão}

Os três modelos econométricos indicados na Tabela 1 apresentam os resultados empíricos do estudo, que utiliza a variável taxa de homicídio juvenil na faixa etária de 15 a 29 anos de idade como dependente e a variável explicativa de interesse, ou seja, despesas com assistência e previdência. 
As estimativas, apresentadas e enunciadas a seguir, utilizam dados em painel em pooled, efeitos aleatórios e efeitos fixos no período 2002 a 2014 para todas as unidades da federação do Brasil. Os resultados empíricos são indicados na Tabela 1, e os respectivos comentários são enunciados em seguida.

Tabela 1 - Impactos sobre a escolaridade no Brasil no período 2002-2014. Dados em painel, efeito aleatório e efeito fixo.

\begin{tabular}{|c|c|c|c|c|c|c|}
\hline \multirow[t]{2}{*}{ Variável } & \multicolumn{2}{|c|}{ Modelo 1 - Pooled } & \multicolumn{2}{|c|}{ Modelo 2 - Efeito aleatório } & \multicolumn{2}{|c|}{ Modelo 3 - Efeito fixo } \\
\hline & Coeficiente & $P>|t|$ & Coeficiente & $P>|t|$ & Coeficiente & $P>|t|$ \\
\hline Escol & $\begin{array}{l}-8,7313^{* *} \\
(3,5024)\end{array}$ & 0,013 & $\begin{array}{l}-8,5685^{* *} \\
(3,6630)\end{array}$ & 0,019 & $\begin{array}{l}-10,8801 \text { **** } \\
(3,9641)\end{array}$ & 0,006 \\
\hline$P o b$ & $\begin{array}{l}-1,2383 * * * \\
(0,2268)\end{array}$ & 0,000 & $\begin{array}{l}-1,5154 * * * \\
(0,2389)\end{array}$ & 0,000 & $\begin{array}{l}-1,7007 * * * \\
(0,2573)\end{array}$ & 0,000 \\
\hline Gini & $\begin{array}{l}54,2371 \\
(49,2336) \\
\end{array}$ & 0,271 & $\begin{array}{l}48,2792 \\
(40,4386)\end{array}$ & 0,233 & $\begin{array}{l}49,1511 \\
(40,5598) \\
\end{array}$ & 0,226 \\
\hline Desemp & $\begin{array}{l}5,0871 * * * \\
(0,6451)\end{array}$ & 0,000 & $\begin{array}{l}2,2174 * * * \\
(0,4913)\end{array}$ & 0,000 & $\begin{array}{l}1,8466 \text { *** } \\
(0,5026)\end{array}$ & 0,000 \\
\hline Cietec & $\begin{array}{l}-0,0059 \\
(0,0207)\end{array}$ & 0,777 & $\begin{array}{l}0,0080 \\
(0,0146)\end{array}$ & 0,582 & $\begin{array}{l}-0,0030 \\
(0,0159)\end{array}$ & 0,848 \\
\hline Despjuscid & $\begin{array}{l}-6,0334 \\
(4,9586)\end{array}$ & 0,225 & $\begin{array}{l}-6,3230^{*} \\
(3,7613)\end{array}$ & 0,093 & $\begin{array}{l}-10,6170 \text { ** } \\
(4,3661)\end{array}$ & 0,016 \\
\hline Assprev & $\begin{array}{l}-0,4841 \\
(0,9247)\end{array}$ & 0,601 & $\begin{array}{l}-0,9009 \\
(0,7311)\end{array}$ & 0,218 & $\begin{array}{l}-1,6442 * * \\
(0,8228)\end{array}$ & 0,047 \\
\hline Consel & $\begin{array}{l}-0,8514 \\
(0,9332)\end{array}$ & 0,362 & $\begin{array}{l}-0,1013 \\
(1,18821)\end{array}$ & 0,932 & $\begin{array}{l}7,3967 * * \\
(3,4085)\end{array}$ & 0,031 \\
\hline Rendam & $\begin{array}{l}1,8622 \\
(8,5432)\end{array}$ & 0,828 & $\begin{array}{l}13,626 * * \\
(7,3508)\end{array}$ & 0,064 & $\begin{array}{l}17,6895^{* * *} \\
(7,4354)\end{array}$ & 0,018 \\
\hline Despec & $\begin{array}{l}-3,6068 * * \\
(1,9776)\end{array}$ & 0,069 & $\begin{array}{l}-1,5652 \\
(1,4088)\end{array}$ & 0,267 & $\begin{array}{l}-1,6550 \\
(1,3986)\end{array}$ & 0,238 \\
\hline Sausan & $\begin{array}{l}9,9833 * * * \\
(2,2435)\end{array}$ & 0,000 & $\begin{array}{l}3,7424 * * \\
(1,9892)\end{array}$ & 0,060 & $\begin{array}{l}-0,6048 \\
(2,3126)\end{array}$ & 0,794 \\
\hline$C$ & $\begin{array}{l}66,2114 * * \\
(29,5485)\end{array}$ & 0,026 & $\begin{array}{l}89,4138 * * * \\
(32,0172)\end{array}$ & 0,005 & $\begin{array}{l}92,4085 * * * \\
(35,4789)\end{array}$ & 0,010 \\
\hline
\end{tabular}

Entre parênteses estão os erros padrões. Nota: $(* * *)$ significante a $1 \% ;(* *)$ significante a 5\%; $(*)$ significante a $10 \%$. Modelo $1: 351$ observações. Modelo 2: 351 observações, Modelo 3: 351 observações, Prob > F = 0,0000. Fonte: Autores.

i) O teste de Hausman aceita a hipótese nula com uma estatística do Qui-quadrado no valor de 23,96 com 11 graus de liberdade e uma probabilidade 0,0109. Nesse contexto, o efeito fixo é o mais indicado.

ii) A variável que representa a escolaridade é estatisticamente significativa nesse estudo e indica uma relação indireta com a taxa de homicídio estudada. Assim, aumentos nos anos de escolaridade proporcionam uma redução nas taxas de homicídio juvenil na faixa etária dos 15 aos 29 anos de idade.

iii) A variável pobreza é estatisticamente significativa, contudo não apresenta o sinal esperado. O resultado sugere estudos adicionais. No entanto, a variável taxa de desemprego é estatisticamente significante e apresenta a relação direta esperada com a variável taxa de homicídios.

iv) A variável que representa a desigualdade de renda não é estatisticamente significativa, no entanto o sinal positivo do coeficiente reflete o resultado esperado, no sentido de que aumentos nessa desigualdade produzem aumentos em homicídios. 
v) A variável que representa a despesa pública em ciência e tecnologia não é estatisticamente significativa, porém o sinal negativo do coeficiente sugere o estudo de um modelo para estudar o resultado esperado e observado, ou seja, ao elevar esses gastos, obtém-se uma redução nas taxas de homicídio juvenil.

vi) Conforme esperado, elevar as despesas em Justiça e direito à cidadania reduz as taxas de homicídio na população de jovens na faixa etária dos 15 aos 29 anos de idade. Assim, sugere que aumentos nas verbas destinadas a essas pastas, podem promover a redução das taxas de homicídios sofridos pela população jovem.

vii) O resultado observado e esperado para a variável que representa a despesa com assistência e previdência é estatisticamente significante nesse estudo e o resultado mostra que promover a assistência e previdência aos trabalhadores e população em geral, gera renda e reduz desigualdades, além de ser, também, redutora das taxas da modalidade de crime aqui estudado. Nesse sentido, o resultado sugere ações que facilitem o acesso aos benefícios.

viii) O consumo de energia elétrica e a renda média de todos os trabalhos são estatisticamente significantes. Assim, a relação direta dessas variáveis com a variável dependente, taxa de homicídio juvenil, podem sugerir ações de segurança, planejamento e orientações às populações residentes nas áreas de risco identificadas de acordo com o os proprietários dessas rendas e consumo.

ix) A despesa em educação e cultura e, em saúde e saneamento, embora não significante no estudo, apresentam o sinal negativo esperado, ou seja, aumentos nesses gastos produzem reduções nos homicídios sofridos pela população jovem.

Por fim, a hipótese assumida nessa pesquisa é confirmada, ou seja, investimentos em assistência e previdência promovem bem estar e reduzem as taxas de homicídios da população juvenil pertencente ao grupo das pessoas na faixa etária de 15 a 29 anos de idade. Dessa forma, os resultados sugerem que os benefícios recebidos pelas famílias geram bem estar coletivo e reduzem esse tipo de crime e, assim, ações que conduzam a facilidades e simplificações para o recebimento precisam ser adotadas.

\section{Considerações Finais}

São inúmeros os debates em todos os segmentos da sociedade para solucionar o problema da criminalidade. Entender a motivação e a dinâmica dos crimes, além de um amplo estudo para implementação de políticas públicas redutoras desse fenômeno é uma estratégia importante para obter êxito nessa redução.

Nesse sentido, ampliar a literatura sobre o assunto pode contribuir bastante para os programas de segurança pública em nosso país. Nesse trabalho, utilizamos dados sobre a taxa de homicídios da população jovem na faixa etária dos 15 aos 29 anos de idade como variável dependente e outras adotadas como explicativas e que refletem as condições socioeconômicas, despesas públicas e consumo para testar e confirmar a hipótese de que aumentos nas despesas com assistência e previdência impactam reduzindo as taxas de homicídio juvenil na faixa etária estudada.

$\mathrm{O}$ estudo com abordagem em três diferentes modelos com dados em painel, pooled, efeito fixo e efeito aleatório, no período 2002-2014 com todas as unidades federativas do Brasil, confirma a hipótese no modelo de efeito fixo, indicado o mais apropriado de acordo com o teste de Hausman, com os resultados apresentados na seção 4.

A variável que representa a escolaridade é estatisticamente significativa nesse estudo e indica uma relação indireta com a taxa de homicídio juvenil. Assim, aumentos nos anos de escolaridade proporcionam uma redução nas taxas dessa modalidade de crime na faixa etária de 15 a 29 anos de idade, resultado observado para a variável pobreza, contudo esse sinal não é o esperado. 
As variáveis que representam a desigualdade de renda e as despesas em ciência e tecnologia, educação e cultura, e saúde e saneamento não são estatisticamente significativas no modelo adotado no estudo, contudo os sinais negativos dos coeficientes apontam a relação inversa desses gastos com a taxa de homicídio, assim um fato importante para a construção de modelos complementares e pesquisa futura.

A taxa de desemprego é estatisticamente significante e mostra a relação direta com a taxa de homicídio juvenil. Assim, sugere a implementação de políticas públicas geradoras de empregos.

As variáveis, renda média de todos os trabalhos e o consumo de energia elétrica, se apresentam significativas e mostram uma relação direta com a variável dependente, que podem sugerir ações de segurança preventivas nas localidades residenciais dos proprietários dessas rendas e consumos.

As despesas essenciais à Justiça e direito à cidadania e, despesas associadas à assistência e previdência se mostram significantes, indicando que aumentos nesses gastos promovem a redução da taxa de jovens vitimados por homicídio. O resultado sugere políticas que potencializem a destinação de verbas para essas pastas, pois podem auxiliar na redução de homicídios e demais crimes.

Por fim, a hipótese assumida nessa pesquisa é confirmada, ou seja, investimentos em assistência e previdência promovem bem estar e reduzem as taxas de homicídios da população juvenil pertencente ao grupo das pessoas na faixa etária de 15 a 29 anos de idade. Dessa forma, os resultados sugerem que os benefícios recebidos pelas famílias geram bem estar coletivo e reduzem esse tipo de crime e, assim, ações que conduzam a facilidades e simplificações para o recebimento precisam ser elaboradas.

Esse trabalho não esgota o assunto, no entanto colabora para o crescimento da literatura ao propor um estudo que aborda os impactos de diversos gastos que podem potencializar na redução das taxas de homicídio em geral, e, em específico nesse trabalho, nas taxas de homicídio da população jovem.

Destaca-se como sugestão de trabalhos futuros, a formulação de novos modelos com outras variáveis explicativas e novas combinações de despesas, que possam contribuir para ampliar e enriquecer a literatura do campo de estudo da Economia do Crime, da Economia, da Segurança Pública e áreas interdisciplinares, além de sugerir novos estudos que conduzam à redução significativa das taxas de crimes no Brasil.

\section{Referências}

Alves, D. F., Oliveira, J. Á. B., da Silva, A. F., \& do O'de Lima Júnior, F. (2017). Níveis de desenvolvimento econômico dos municípios cearenses sob a perspectiva da criminalidade. Revista Nexos Econômicos, 11(1), 36-53.

Becker, G. S. (1968). Crime and punishment: An economic approach. In The economic dimensions of crime (pp. 13-68). Palgrave Macmillan, London.

Cano, I. \& Ribeiro, E. (2007). Homicídios no Rio de Janeiro e no Brasil: dados, políticas públicas e perspectivas. In: Cruz MUG, Batitucci ECO, eds. Homicídios no Brasil. Rio de Janeiro: FGV, p. 51-78.

Cerqueira, D. (2021). Atlas da violência 2021. IPEA.

Cerqueira, D., \& Lobão, W. (2004). Determinantes da criminalidade: arcabouços teóricos e resultados empíricos. Dados, 47, $233-269$.

de Carvalho, R. C., \& Taques, F. H. (2014). A desigualdade de renda e a educação podem explicar a criminalidade? Uma análise para os Estados brasileiros. Revista de Políticas Públicas, 18(2), 343-357.

de Morais Colombaroli, A. C., \& Agapito, L. S. (2016). Segurança Pública no Brasil: O que tem sido Feito em Relação aos Homicídios? Revista de Criminologias e Politicas Criminais, 2(1), 40-56.

Ervilha, G. T., \& Lima, J. E. D. (2019). Um método econométrico na identificação dos determinantes da criminalidade municipal: a aplicação em Minas Gerais, Brasil (2000-2014). Economía, sociedad y territorio, 19(59), 1059-1086.

Fávero, L. P., \& Belfiore, P. (2021). Manual de análise de dados: estatística e modelagem multivariada com Excel®, SPSS® e Stata®. Elsevier Brasil.

Fortunato, M. A. B. (2009). Morbimortalidade por causas externas no Distrito Federal e Entorno: 2002-2007.

Furqan, M., \& Mahmood, H. (2020). Does education reduce homicide? A panel data analysis of Asian region. Quality \& Quantity, 54(4). 
Gil, A. C. (2008). Métodos e técnicas de pesquisa social. (6a ed.), Ediitora Atlas SA.

Goha, L. T., Kalliapan, S. R., \& Ishak, S. (2018). Income inequality and crime: evidence from a dynamic panel data approach. Int. J. Econs \& Mgmt, 12(S2), $479-490$.

Gujarati, D. (2019). Econometria: Princípios, teoria e aplicações práticas. Saraiva Educação SA.

Hamberger, P. A. D. V., Araujo, V. M., \& Valle, A. C. M. D. (2019). Economia e criminalidade: uma análise de dados em painel das mesorregiões de Minas Gerais no período 2005-2007.

Hausman, J. A. (1978). Specification tests in econometrics. Econometrica: Journal of the econometric society, 1251-1271.

Kauark, F. D. S., Manhães, F. C., \& Medeiros, C. H. (2010). Metodologia da pesquisa: um guia prático.

Loureiro, P. R., Moreira, T. B. S., \& Ellery, R. (2017). The relationship between political parties and tolerance to criminality: A theoretical model and empirical evidences for Brazil. International Journal of Social Economics.

Loureiro, P., Mendonça, M. J., \& Sachsida, A (2003). Criminalidade e interação social. TEXTO PARA DISCUSSÃO N_, 968.

Máquina, C. M., Maria, E. da C. J., Nhongo, E. J. S., \& Come, S. F. (2021). Desigualdade social como vetor dos homicídios no Estado de São Paulo, Brasil. Research, Society and Development, 10(12), e176101220237.

Marconi, M. D. A., \& Lakatos, E. M. (2017). Fundamentos de metodologia científica. 8. ed.-São Paulo: Atlas.

Moraes, M. J. S. M., \& Chaves, A. B. P. (2020). Adolescente infrator: reincidência e vitimização por homicídio. Research, Society and Development, 9(8), e496985998-e496985998.

Nogueira, V. D., Gomes, L. M. X., \& de Andrade Barbosa, T. L. (2018). Tendência da mortalidade por homicídio em Foz do Iguaçu e Paraná, 2010 a 2015. Revista Brasileira de Iniciação Científica, 5(2), 222-234.

Olini, R. M., Daniel, L. P., Dalfovo, W. C. T., Orlandi, M., \& Shikida, P. F. A. (2018). Homicídio e desigualdade de renda: uma análise espacial para o estado de Mato Grosso em 2000 e 2010. Economic Analysis of Law Review, 9(3), 107-130.

Oliveira, C. M. S. D. (2016). Criminalidade no Brasil e seus aspectos econômicos no período 1990-2010: uma análise de vetores autorregressivos para dados em painel-PVAR (Master's thesis, Universidade Federal do Rio Grande do Norte).

Oliveira, D. X. A. D. (2019). Os impactos da criminalidade em uma análise teórica, empírica e espacial.

Paula, J. C. D. (2010). Aqui tem violência?: as representações sociais de violência urbana dos moradores da Ceilândia.

Pinto, A. M., Farias, J. J. Costa, R. F., \& Lima, F. S. (2018). Uma análise dos determinantes da taxa de crimes de homicídios nos estados do Brasil: uma aplicação em painel dinâmico. Revista de Economia Regional, Urbana e do Trabalho, 7(2), 35-52.

Regateiro, H. A. S., Ramos, E. M. L. S., Souza, J. G., \& Mello, C. M. de A. (2021). Avaliação da criminalidade no Estado do Pará. Research, Society and Development, 10(3), e10010313088.

Sachsida, A., \& de Mendonça, M. J. C. (2013). Evolução e determinantes da taxa de homicídios no Brasil (No. 1808). Texto para Discussão.

Seillier, M. (2012). Criminalidade nos estados brasileiros no período 2001-2005: uma análise econômica com dados em painel.

Sousa Lucas, M., da Cunha, M. S., \& de Lucas Bondezan, K. (2020). Determinantes socioeconômicos da criminalidade no estado do Paraná: uma análise espacial. Revista de Economia, 41(75).

Spaniol, M. I., Moraes Jr, M. C., \& Rodrigues, C. R. G. (2020). Como tem sido planejada a Segurança Pública no Brasil? Análise dos Planos e Programas Nacionais de Segurança implantados pós-redemocratização. Revista Brasileira de Segurança Pública, 14(2), $100-127$.

Viano, E. C. (2007). Homicídio: uma perspectiva vitimológica. Homicídios no Brasil, 105-124.

Waiselfisz, J. J. (2016). Mapa da violência 2016: homicídios por armas de fogo. Secretaria Nacional de Juventude moderna. São Paulo: Cengage Learning.

Wooldridge, J. M. (2010). Introdução à econometria: uma abordagem moderna. Cengage Learning. 